Document downloaded from:

http://hdl.handle.net/10251/66539

This paper must be cited as:

Doménech Antich, EM.; Botella Grau, MS.; Ferrús Pérez, MA.; Escriche Roberto, MI. (2013). The role of the consumer in the reduction of Listeria monocytogenes in lettuces by washing at home. Food Control. 29(1):98-102. doi:10.1016/j.foodcont.2012.05.074.

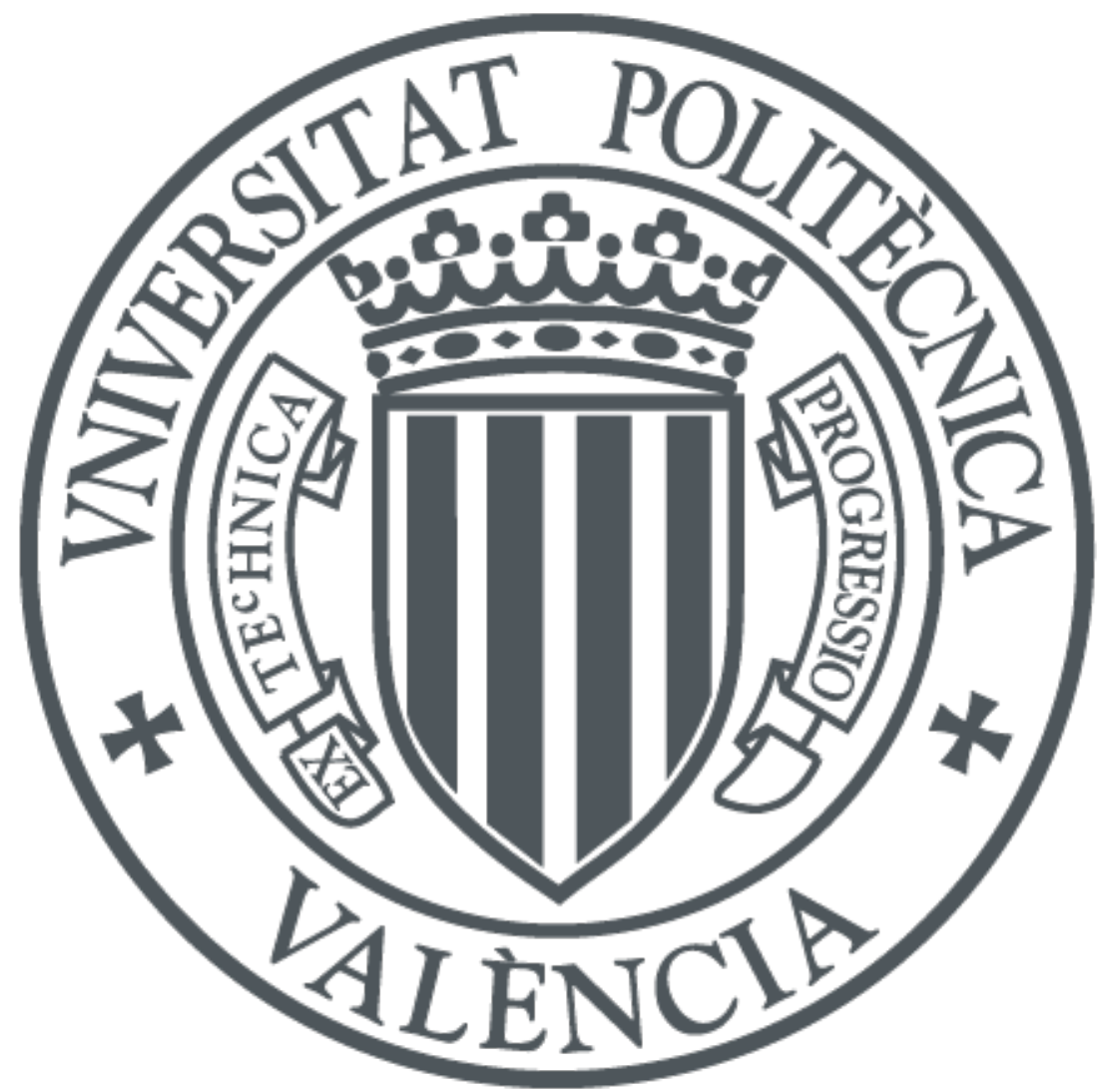

The final publication is available at

https://dx.doi.org/10.1016/j.foodcont.2012.05.074

Copyright Elsevier

Additional Information 


\title{
The role of the consumer in the reduction of Listeria monocytogenes in lettuces by washing at home
}

\author{
E. Domenech ${ }^{1}$, S. Botella ${ }^{2}$, M. A. Ferrús ${ }^{2}$, I. Escriche ${ }^{1}$
}

${ }^{1}$ Departamento de Tecnología de Alimentos, Instituto de Ingeniería de Alimentos para el Desarrollo, Universidad Politécnica de Valencia, 46022 Valencia, Spain;

${ }^{2}$ Centro Avanzado de Microbiología de Alimentos, Camino de Vera, s/n 46022 Valencia. Department of Biotechnology, Universitat Politècnica de València, Spain

\begin{abstract}
Lettuce is highly appreciated for its nutritional properties; however microbial contamination through the food chain and its raw consumption may jeopardize these known benefits to the diet. The objective of this study was to determine the role of the consumer at the stage of washing at home, in relation to the probability of illness due to the presence of Listeria monocytogenes in lettuce. Survival curves of L. monocytogenes after washing (dipping with and without addition of bleach, and washing under a running tap) were studied. A mathematical model for each washing method was calculated by fitting experimental data. The obtained models were used to estimate the probability of illness after washing at home. Results show that although consumers can only deal with low loads of $L$. monocytogenes, their role is essential to reduce the normal contamination level of lettuces and ensure their safety.
\end{abstract}

\section{Introduction}

Lettuce is one the most brought and consumed vegetables in Europe and the USA. More than a third of the population eat lettuce once a week on average, while three quarters eat salad three times in the same period, meaning there is potential for increased consumption (USDA/Economic Research Service, 2010). Fresh produce is not a common vehicle for foodborne diseases compared with other types of foods. However, absolute safety is not possible and various foodborne pathogenic microorganisms as Listeria monocytogenes have been linked to cases of foodborne infection and isolated from many different varieties of fresh fruit and vegetables (Li-Cohen and Bruhn, 2002; Stopforth et al., 2008).

Antimicrobial agents are often added to the water used to wash fresh fruit and vegetables to reduce the number of microorganisms (Zhang, el al., 2009). Many different disinfectants and application methods have been studied for this purpose in the food industry, for example peoxyacetic acid, chlorine dioxide, ozone, electrolyzed water, chlorine, etc., (Vijayakumar \& WolfHall, 2002; Rodgers et al., 2004; Kondo et al 2006; Zhang, et al., 2009). Of all of them, chlorination is considered to be one of the best ways to minimize the transmission of pathogens and is the most commonly used sanitizer to treat fresh products (Stopforth, et al., 2008). Sodium hypochlorite is a powerful disinfectant with oxidizing properties, which is active against a wide spectrum of organisms, such as L. monocytogenes and is non-toxic to humans at low concentrations (Dychdala, 1991; Nieuwenhuijsen et al., 2005).

Preventing foodborne disease requires the cooperation of all the agents (administration, company and consumers) in the food chain. Following this tendency, Doménech et al, 2007 presented the fundamentals of the QRA model from a production perspective to 
assure food safety under the principles of an integrated framework. This permits consideration of all the agents involved in decision-making on food quality and safety, and all the stages of the food chain, from the farm to fork. Within this framework from the farm to table, most of the progress aimed at the improvement of food safety and quality has been focused on hazard control in primary and secondary production, processing, storage and distribution (Angelillo et al., 2001). Consumers are considered to be the last line of defence against foodborne illness. In fact, proper food handling at home can maintain a hazard at a safe level even reduce it.

The objective of this study was to determine the role that the consumer plays, at the stage of washing at home, in relation to the exposure to risk due to the presence of L. monocytogenes in lettuce at retail. With this aim in mind, inactivation of this microorganism with different washing methods (dipping with and without the addition of bleach, and washing under a running tap) were studied. Experimental data were fitted to mathematical equations. The resulting models were used to determine the probability of illness and to test whether the protection level recommended by the U.S. Healthy People 2020 initiative (USHP, 2011) is achieved.

\section{Material and methods}

2.1. Preparation of Listeria monocytogenes innoculum

L. monocytogenes CECT 936 (Spanish Type Culture Collection, Valencia, Spain) was used in this study. Strains were maintained at $4^{\circ} \mathrm{C}$ on Palcam (Oxoid, Cambridge) slants. A loopful was transferred to $10 \mathrm{~mL}$ FRASER broth (Sharlau, Barcelona) followed by incubation at $37^{\circ} \mathrm{C}$ for $24 \mathrm{~h}$ to achieve a final cell number of approximately $10^{8} \quad \mathrm{CFU} / \mathrm{mL}$. Final concentrations of the inoculum solutions were confirmed by making serial dilutions in deionized water, plated onto Palcam agar (Oxoid, Cambridge) supplemented with 06-110 CASE (Sharlau, Barcelona) and incubated for $24-48 \mathrm{~h}$ at $37^{\circ} \mathrm{C}$. A final transfer of $10 \mathrm{~mL}$ of $L$. monocytogenes culture was added to $1 \mathrm{~L}$ of sterile deionized water.

\subsection{Lettuce inoculation}

Fresh lettuces were obtained from a local wholesale market in Valencia and transported to the laboratory. The product was physically inspected, the core and the wrapper leaves were discarded and selected lettuce leaves were cut into $2.5 \mathrm{~g}$ pieces using a sharp knife at room temperature. All samples were stored at $4 \pm 2^{\circ} \mathrm{C}$ for a maximum of $24 \mathrm{~h}$ before the inoculation process was carried out. The fresh-cut lettuce was completely immersed in the inoculum solution and kept under constant agitation for $10 \mathrm{~min}$ at room temperature.

\subsection{Solutions and treatment}

Chlorine and control solutions, for the dipping treatment, were made immediately before use. The control solution was made with tap water alone, which had a chlorine concentration of $0.7 \mathrm{ppm}$. Chlorine solutions were made by diluting sodium hypochlorite (commercial bleach suitable for food and water sanitising) in the control solution, to achieve concentrations of 4 ppm (approximately two drops), 8 ppm (approximately four drops) and $40 \mathrm{ppm}$ (approximately $1 \mathrm{~mL}$ of bleach). Concentrations were verified with chlorine concentration test strips (Advantec MHS, Inc., Dublin, CA). In order to simulate real conditions at home, $\mathrm{pH}$ was not corrected. Values for each concentration of chlorine were $7.93 \pm 0.13 ; 8.08 \pm 0.09$; and $9.19 \pm$ 0.094 respectively. 


\subsection{Washing stage}

For the dipping treatment, $25 \mathrm{~g}$ portions of inoculated cut lettuce were transferred from the inoculation container into new ones, which contained the solutions with different concentrations of chlorine: control $(0.7$ ppm) and added chlorine (4, 8, 40 ppm) at room temperature for 5,15 and 30 minutes of contact time.

For the washing under a running tap water treatment, $25 \mathrm{~g}$ portions of inoculated cut lettuce were transferred to be rinsed for 10, 20, 30, 45 and 60 seconds under running tap water $(0.7 \mathrm{ppm})$ at a constant flow rate $2 \mathrm{~L} / \mathrm{min}$.

A sodium thiosulphate neutralizing solution was prepared to neutralise the hypochlorite at the end of each established exposure time, prior to analysis of the samples.

\subsection{Microbial analysis}

A $25 \mathrm{~g}$ portion of each treatment sample was aseptically transferred into a stomacher bag. Samples were homogenized with $225 \mathrm{~mL}$ sterile Fraser broth for 1 min using a Seward Laboratory Homogeneizator (AGB Scientific, Dublin, Ireland). Serial dilutions for each homogenized sample were made in deionized sterile water and plated onto Palcam agar, supplemented with 06-110 CASE. Typical colonies were counted after incubation at $37^{\circ} \mathrm{C}$ for $48 \mathrm{~h}$ to determine the survival of $L$. monocytogenes. Counts of this microorganism were performed by following the UNEEN/ISO 11290-2 enumeration method. Bacterial counts were expressed as Log $\mathrm{CFU} / \mathrm{g}$ of lettuce. All analyses were made in triplicate.

\subsection{Predictive reduction models}

The empirical values of $L$. monocytogenes obtained after dipping lettuce in different chlorine treatment solutions and contact time were adjusted to the model shown in Eq.(1), suggested by Peleg (2002)

$$
\log (N / N o)=-b(C) t^{n(C)}
$$

Where " $N_{0}$ " is the initial number of cells (CFU/g), "N" the number of survivals after washing treatment, " $t$ " is time of washing and " $b(C)$ " and " $n(C)$ " are concentration dependent coefficients defined by empirical relationships, Eq. (2) and Eq. (3), respectively.

$$
\begin{aligned}
& b(C)=C / k_{1}+k_{2} C \\
& n(C)=k_{3}+k_{4} C^{k_{5}}
\end{aligned}
$$

where " $C$ " is the concentration of sodium hypochlorite and " $k_{1}, k_{2}, k_{3}, k_{4}$, $k_{5}$ " are constants. The values of the different constants were obtained fitting our experimental data with the help of the statistical program Statgraphics version Centurion XIV for nonlinear regression analysis.

The model for washing under running tap water was also obtained with the empirical values of $L$. monocytogenes by fitting with the Statgraphics version Centurion XIV to a logarithmic equation, Eq. (4), where " $t$ " is time of washing and " $a$ " and " $b$ " are constants .

$$
\log (N / N o)=a \operatorname{Ln}(t)+b
$$

The goodness of the fit of both models was assessed using the mean square error (MSE), regression coefficients $\left(\mathrm{R}^{2}\right)$, accuracy factor $\left(\mathrm{A}_{f}\right)$, and the bias factor (B).

\subsubsection{Mean square error (MSE)}

The smaller the MSE values, the better the fit of the model to the data (Chen \& Hoover; 2003) Eq (5).

MSE $=\sum(\text { predicted }- \text { observed })^{2} /(n-p)$ 
where, "predicted" is the predicted values applying the model, "observed" is experimentally observed data, " $n$ " stands for the number of observations, and " $p$ " the number of parameters to be estimated.

\subsubsection{Regression coefficients $\left(\mathrm{R}^{2}\right)$ values}

The higher the value, the better the adequacy of the model to describe the data (Chen \& Hoover; 2003). A value of " 1 " indicates that the model produces a perfect fit to these data.

\subsubsection{Accuracy factor $\mathrm{A}_{f}$}

The accuracy factor was proposed by Ross (1996) to evaluate the performance of predictive models. This factor provides a measure of the average difference between observed and predicted values, Eq (6).

$\mathrm{A}_{f}=10^{\sum \mid \text { (predicted / observed) } \mid / n}$

The larger the $\mathrm{A}_{f}$ value, the less accurate the average estimate, while a value of " 1 " indicates a perfect fit to data.

\subsubsection{Bias factor}

The bias factor is defined as Eq (7). Perfect agreement between prediction and observations will lead to a bias factor of " 1 ". In the case of a death model, a bias factor greater than one indicates that the model predicts a higher number of survivors than are observed. Conversely, a bias factor less than one indicates that the model predicts a lower number of survivors than are observed.

Bias factor $=10 \sum$ (predicted / observed $) / n$

\subsubsection{Statistical analysis}

In order to ascertain whether the factors: time and concentration of sodium hypochlorite (bleach) are significant in the reduction of $L$. monocytogenes, an analysis of variance
(ANOVA) was conducted using Statgraphics Centurión XVI. The level of significance was set at $p<0.05$ for all comparisons.

\subsubsection{Simulation}

The assessment of risk due to $L$. monocytogenes on consumption was obtained by simulation, using a Monte Carlo procedure. 10000 iterations per simulation were run using Latin Hypercube sampling. The simulation was built as a spreadsheet model in Microsoft Excel with the@Risk 4.5 (Palisade Newfield) add-on.

For the simulation it was necessary to combine: predictive models, initial load, washing conditions and doseresponse curve. In this case, the obtained predictive models from laboratory results were applied. Also, four initial loads were considered, i.e. normal microbial load in the market and abnormal doses fixed at 3,6, and $9 \log$ $(\mathrm{CFU} / \mathrm{g})$. Table 1 presents the data used in the simulation of the stage of washing at home. The initial load (retail) is the result of adjusting the data obtained from Abadias et al., 2008 to a probabilistic density function. Distribution of the dipping time, dose of bleach and washing under running tap water were obtained from a survey made in Valencia, where consumers were asked about their behaviour in the handling of vegetables (Doménech et al., 2010). In relation to washing methods, the percentages considered were $4 \%$ of people do not wash vegetables, $84 \%$ wash them under running water, $11 \%$ place the vegetables in a bowl of water, and only $1 \%$ also add chlorine or a commercial solution to the water in the bowl (Li-Cohen and Bruhn, 2002). Table 2 shows the doseresponse values proposed by FDA/USDA, (2003), which were used to estimate the probability of illness due 
to the consumption of lettuce contaminated with L. monocytogenes.

\subsubsection{Suitability of results}

The U.S. Healthy People 2020 initiative, in relation to the level of protection (ALOP), aimed to reduce the rates of listeriosis by 50 percent, to 2 cases per million per year for a base population, for all foods, and all contamination levels (USHP, 2011). Taking into account that the consumption of lettuce in Spain is around $7.56 \mathrm{~kg}$ per person per year and the size of each serving is $50 \mathrm{~g}$ (MAPA, 2009), the probability of illness must be less than 1.32E-8 listeriosis cases per serving to attain this level of protection.

\section{Results}

\subsection{The dipping model}

Table 3 shows the reduction of $L$. monocytogenes obtained after dipping lettuces for different times and doses of bleach, in terms of the mean values (Log CFU/g) and the standard deviations. The results confirm a decrease between 1 and 2 logs depending on the dose (from 4 to 40ppm) and the exposure time (from 1 to 30 minutes). Both parameters are significant, time ( $\mathrm{p}$-value $=0.0306)$ and dose $(p$-value $=0.0003) . \quad$ Nevertheless, non significant differences exist between 5 and 15 minutes. Only when dipping is carried out after 30 minutes are significant differences appreciated. In relation to the dose, significant differences are only observed when bleach is added, however non significant differences are observed between 4,8 and 40ppm.

Fitting the obtained values in this study to the equations 1-3 proposed by Peleg, 2002, gave the predictive model shown in Eq. (7) where " $C$ " is dose of hypochlorite and " $t$ " is dipping time. $\log (N / N o)_{\text {Dipping }}=(-C / 0.35+0.65 * C) \quad *^{-}$ $0.44+0.54 * C^{\wedge}-0.003$

The good fit at all times and disinfectant doses studied in the predictive dipping model was supported by the values obtained for MSE (0.011), Bias factor (1.0001), $\mathrm{R}^{2}$ (98.13) and accuracy factor (1.04).

3.2. Modelling washing under running tap water

Table 4 shows the results obtained for washing under running tap water. In this case, the dose does not change and it is approximately $0.7 \mathrm{ppm}$. The only parameter modified was the time that cut lettuce was under the tap water. As we can observe the main reduction was achieved in the first thirty seconds. In this case, a reduction of 1 Log was possible.

The obtained values were fitted to a logarithmic equation. The predictive model is expressed as Eq 8, where " $t$ " is time of washing.

$\log (N / N o)_{\text {washing }}=-0,28 \operatorname{Ln}(t)-0,0103$

The good fit obtained between the observed values and the values predicted by the washing under running tap water model were supported with the values obtained for MSE (0.0032); Bias factor (1.00), $\mathrm{R}^{2}$ (98.92) and the accuracy factor (1.04).

\subsection{Risk assessment}

Table 5 shows the probability of illness at home due to the prevalence of L. monocytogenes after the stage of washing at home. The values were expressed in each case by the mean, $5 \%$ and $95 \%$ percentile. The results showed that for the normal microbial load in the market and the mean value for the abnormal dose of $3 \mathrm{Log}(\mathrm{CFU} / \mathrm{g})$ the 
level of protection proposed by the U.S. Healthy People 2020 would be achieved, however, if the doses were 6, or $9 \log (\mathrm{CFU} / \mathrm{g})$ this level of protection would not be obtained.

Table 6 shows the sensibility study carried out in relation to the type of washing and initial dose. The results showed that for the normal contamination of L. monocytogenes, where only $0.1 \%$ of the samples were higher than $100 \mathrm{CFU} / \mathrm{g}$, any type of washing achieves the protection level recommended by the U.S. Healthy People 2020 initiative (USHP, 2011). When the dose reaches $3 \mathrm{logs} \mathrm{CFU} / \mathrm{g}$, washing under running tap water is not enough and dipping with or without bleach is necessary. However, when the contamination is high, 6 or $9 \log$ $\mathrm{CFU} / \mathrm{g}$, none of the studied treatments are effective.

\section{Discussion}

A series of experiments were conducted to analyse the role that the consumer plays in the reduction of risk exposure due to $L$. monocytogenes prevalence according to how the stage of washing at home is performed. All treatments tested were capable of reducing $L$. monocytogenes to some extent, however, the effects varied from 0.60 to 1.97 logs depending on the concentration of bleach and exposure time. In all cases, the inoculation and dipping model represents fresh or recent contamination of the product. In theory, this type of contamination would be easier to remove as there is no time for adherence of the bacteria to the surface or to biofilms (Behrsing et al., 2000). Similar results were found in previous studies, which show that chlorine rinses can decrease the bacterial load by values ranging from $<1 \log \mathrm{CFU} / \mathrm{g}$ to $3.15 \log \mathrm{CFU} / \mathrm{g}$ depending on the inoculation method, chlorine concentration, contact time, and the target bacteria tested (Zhang and Farber, 1996; Keskinen \& Annous, 2011).

Dipping lettuces in $1 \mathrm{~mL}$ of bleach per litre for 30 minutes was the most effective treatment, reaching a reduction of approximately $2 \mathrm{LogCFU} / \mathrm{g}$. However, with the same dosage, the differences in the reduction reached after 5 and 15 minutes were not significant. Adams et al., 1989 reported that increasing the exposure time of lettuce in a hypochlorite solution from 5 to 30 minutes did not further decrease total microbial numbers. Similarly Zhang \& Farber, 1996 found that the load of L. monocytogenes decreased only marginally with increased exposure time from 1 to 10 minutes, regardless of the chlorine concentration. Taking into account the dose factor, a significant difference exists between lettuce dipped with and without bleach, however no significant difference exists between two drops and $1 \mathrm{~mL}$. This may be because in this study $\mathrm{pH}$ was not corrected, in order to better simulate real domestic conditions. Nevertheless, effectiveness against microorganisms depends on this parameter, in fact, when $\mathrm{NaClO}$ is added to water, $\mathrm{pH}$ increases and hypochlorous acid ( $\mathrm{HOCl})$, which is the active antimicrobial component, dissociates readily to hypochlorite ions $\left(\mathrm{OCl}^{-}\right)$or chlorine gas $\left(\mathrm{Cl}_{2}\right)$, which produces a loss of effectiveness (Boyette et al., 1993; Suslow, 2004). On the other hand, washing under running tap water permits a maximum reduction of the initial load to $1 \mathrm{LogCFU} / \mathrm{g}$, reaching this value in approximately 30 seconds; however for the most frequent washing time at home (10 seconds) the reduction is only $0.6 \mathrm{LogCFU} / \mathrm{g}$.

The adjustment of the experimental data to a mathematical equation results in a predictive model that can aid food safety management, since it can be used to simulate the evolution of a hazard according to the characteristic 
conditions at a given stage or at the end of the food chain (Walls \& Scott, 1997; Nauta, 2002; Oscar, 2004; Doménech et al., 2009; Membré \& Lambert 2008). The semi logarithmic survival curves of microorganisms exposed to lethal agents, chemical agents included, is frequently nonlinear (LeClair, et al., 1994; El-Shenawy and Marth 1998; Avsaroglua, et al., 2007; Koseki and Yamamoto, 2007). The application of the model proposed by Peleg 2002 for sigmoid survival curves, to the results obtained in the laboratory for different doses of bleach and time in the dipping water, and the logarithmic function model for reduction in washing under a running tap for 1 minute, were successful as indicated by the goodness of fit assessed using the mean square error (MSE), regression coefficients $\left(\mathrm{R}^{2}\right)$, accuracy factor $\left(\mathrm{A}_{f}\right)$, and the bias factor (B). Application of these models with good results were also found by other authors (San Martín et al., 2007; Bermúdez-Aguirre et al., 2009; Raffellini et al., 2011; López-Gálvez, et al., 2012).

The obtained models provide a useful tool to investigate the risk to consumers depending on the initial load at retail and the method of washing at home. The results demonstrate that only when the L. monocytogenes load is less than $3 \log (\mathrm{CFU} / \mathrm{g})$ is the level of protection proposed by the U.S. Healthy People 2020 initiative (USHP, 2011) achieved. For this reason, although consumers can only deal with low loads of L. monocytogenes, their role is essential in reducing the normal contamination level of lettuces and ensuring their safety.

\section{Acknowledgments}

This study was supported by the Universidad Politécnica de Valencia, Spain (PAID 06-10), which the authors gratefully acknowledge.

\section{References}

Abadias, M., Usall, J., Anguera, M., Solsona, C., \& Viñas, I. (2008) Microbiological quality of fresh minimally-processed fruit and vegetables, and sprouts from retail establishments. International Journal of Food Microbiology, 123, 121-129.

Adams, M.R., Hartley, A.D., \& Cox, L.J. (1989). Factors affecting the efficiency of washing procedures used in the production of prepared salads. Food Microbiology, 6, 69-77.

Angelillo, I.F., Viggiani, N.M.A., Greco, R.M., \& Rito. D. (2001). HACCP and food hygiene in hospitals: Knowledge, attitudes, and practices of food-services staff in Calabria, Italy. Infection Control and Hospital Epidemiology, 22 (6), 363369.

Avsaroglua, M.D., Buzrula, S., Alpasa, H., \& Akcelik M. (2007). Hypochlorite inactivation kinetics of lactococcal bacteriophages. LWT - Food Science and Technology 40(8), 1369-1375.

Behrsing, J., Winkler, S., Franz, P., \& Premier, R. (2000). Efficacy of chlorine for inactivation of Escherichia coli on vegetables. Postharvest Biology and Technology, 19, 187-192.

Bermúdez-Aguirre, D., Corradini, M.G., Mawson, R. \& Barbosa-Cánovas, G.V. (2009). Modeling the inactivation of Listeria innocua in raw whole milk treated under thermo-sonication. Innovative Food Science \& Emerging Technologies 10 (2), 172-178.

Boyette, M., Ritchie, D., Carballo, S., Blankenship, S., \& Sanders, D. (1993). Chlorination and postharvest disease control. HortTechnol., 3, 395-400.

Chen, H., \& Hoover, D.G. (2003). Modeling the combined effect of high hydrostatic pressure and mild heat on the inactivation kinetics of Listeria monocytogenes Scott A in whole milk. Innovat. Food Sci. Emerg. Technol. 4, 25-34.

Doménech, E., Escriche, I. \& Martorell, S. (2007). Quantification of risks to 
consumers' health and to company's incomes due to failures in food safety. Food Control, 18, 1419-1427.

Doménech, E., Escriche, I. \& Martorell, S. (2009). An approach for assessing CCP effectiveness in food production applications by predictive QRA modeling. Reliability Engineering \& System Safety, 94(9), 1451-1460.

Doménech, E., Ferrus, M.A., Conchado, A., Gallart L., \& Escriche, I. (2010). Consumer survey on the handling of frozen vegetables from the shop to consumption. International Conference on Food Innovation. FoodInnova 2010.

Dychdala, G.R. (1991). Chlorine and chlorine compounds. In Disinfection, Sterilization and Preservation ed. Block, S.S. pp. 131 - 151. Philadelphia: Lea \& Febiger

El-Shenawy, M. A., \& Marth, E. H. (1988). Inhibition of Listeria monocytogenes by sorbic acid. Journal of Food Protection, 51, 842-846.

FDA/USDA (2003). Quantitative Assessment of Relative Risk to Public Health from Foodborne Listeria monocytogenes. Among Selected Categories of Ready-toEat Foods. http://www.foodsafety.gov/ dms/lmr2toc.html

Kondo, N., Murata, M., \& Isshiki, K. (2006) Efficiency of sodium hypochlorite, fumaric acid, and mild heat in killing native microflora and Escherichia coli O157:H7, Salmonella typhimurium DT104, and Staphylococcus aureus attached to fresh-cut lettuce. Journal of Food Protection 69(2), 323-9.

LeClair, K., Heggart, H., Oggerl, M., Barlett, F. M., \& McKellar, R. C. (1994). Modeling the inactivation of Listeria monocytogenes and Salmonella typhimorium in simulated egg wash water. Food Microbiology, 11, 345-349.

Li-Cohen, A.E. \& Bruhn C.M.. (2002). Safety of consumer handling of fresh produce from the time of purchase to the plate: A comprehensive consumer survey. Journal of Food Protection 65(8),12871296.

López-Gálvez, F., Posada-Izquierdo, G.D., Selma, M.V., Pérez-Rodríguez, F., Gobet, J., Gil, M.I. \& Allende, A.
(2012). Electrochemical disinfection: An efficient treatment to inactivate Escherichia coli $0157: \mathrm{H} 7$ in process wash water containing organic matter. Food Microbiology, 30(1), 146-156.

Keskinen, L.A., \& Annous, B.A. (2011). Efficacy of adding detergents to sanitizer solutions for inactivation of Escherichia coli $\mathrm{O} 157: \mathrm{H} 7$ on Romaine lettuce. International Journal of Food Microbiology, 147(3), 157-161.

Koseki, S., \& Yamamoto, K. (2007). A novel approach to predicting microbial inactivation kinetics during high pressure processing. International Journal of Food Microbiology 116, 275-82.

MAPA 2009. Consumption in Spain. Ministerio Agricultura, Pesca y Alimentación. http://www.mapa.es/es/alimentacion/pag s/consumo/BD/consulta09.asp

Membré, J.M., \& Lambert R.J.W. (2008). Application of predictive modelling techniques in industry: From food design up to risk assessment. International Journal of Food Microbiology, 128(1), $3010-15$.

Nauta M.J. (2002). Modelling bacterial growth in quantitative microbiological risk assessment: is it possible?. International Journal of Food Microbiology, 73, 297304.

Nieuwenhuijsen, M.J. (2005). Adverse reproductive health effects of exposure to chlorination disinfection by products. Global NEST Journal, 7(1), 128-144.

Oscar T. (2004). A quantitative risk assessment model for Salmonella and whole chickens. International Journal of Food Microbiology, 93, 231-247.

Peleg, M. (2002). Modeling and simulation of microbial survival during treatments with a dissipating lethal chemical agent. Food Research International 35, 327-336.

Raffellini, S., Schenk, M., Guerrero, S., \& Alzamora, S.M. (2011). Kinetics of Escherichia coli inactivation employing hydrogen peroxide at varying temperatures, $\mathrm{pH}$ and concentrations. Food Control, 22, (6), 920-932.

Rodgers, S.L., Cash, J.N., Siddiq, M., \& Ryser, E.T. (2004). A Comparison of Different Chemical Sanitizers for Inactivating Escherichia coli $\mathrm{O} 157: \mathrm{H} 7$ and Listeria 
monocytogenes in Solution and on Apples, Lettuce, Strawberries, and Cantaloupe. Journal of Food Protection, 67(4), 721-731

Ross, T. (1996). Indices for performance evaluation of predictive models in food microbiology. Journal of Applied Microbiology, 81, 501-508.

San Martín, M.F., Sepúlveda, D.R., Altunakar, B., Góngora-Nieto, M.M., Swanson, B.G., \& Barbosa-Cánovas, G.V. (2007). Evaluation of selected mathematical models to predict the inactivation of Listeria innocua by pulsed electric fields. LWT - Food Science and Technology. .40(7), 1271-1279.

Stopforth, J.D., Mai, T., Kottapalli, B. \& Samadpour, M. (2008). Effect of Acidified Sodium Chlorite, Chlorine, and Acidic Electrolyzed Water on Escherichia coli O157:H7, Salmonella, and Listeria monocytogenes Inoculated onto Leafy Greens. Journal of Food Protection, 71(3), 625-628.

Suslow, T.V. (2004). Oxidation-reduction potential (ORP) for water disinfection monitoring, control and documentation. University of California, Division of Agriculture and Natural Resources Publication no. 8149
USDA/Economic Research Service. Date last updated February 1, 2010. http://www.ers.usda.gov/Data/FoodCons umption/app/reports/displayCommoditie s.aspx?reportName $=$ Individual + vegetabl e\&id=24\#startForm

USHP (U.S. Healthy People). (2011). Topics \& Objectives Index-Healthy People 2020.

Vijayakumar, C. \& Wolf-Hall C.E. (2002). Minimum bacteriostatic and bactericidal concentrations of household sanitizers for Escherichia coli strains in tryptic soy broth. Food Microbiology, 19(4), 383388 .

Walls I. \& Scott V. (1997). Use of predictive microbiology in microbial food safety risk assessment. International journal of food microbiology, 36, 97-102.

Zhang, S. \& Farber, J.M. (1996). The effects of various disinfectants against Listeria monocytogenes on fresh-cut vegetables. Food Microbiology, 13: 311-321.

Zhang, G., Vanessa, L.M., Phelan, H., \& Doyle, M.P. (2009). Efficacy of antimicrobial agents in lettuce leaf processing water for control of Escherichia coli O157:H7. Journal of Food Protection, 72(7), 13921397.

Table 1. Washing conditions used in the simulation

\begin{tabular}{lll}
\hline Description & Value & Units \\
\hline Initial load & Lognorm $(1,09 ; 0,226)$ & CFU/g \\
Dipping time & BetaGeneral $(6,21 ; 15,817 ; 1 ; 30)$ & $\mathrm{min}$ \\
Running water time & Betageneral $(1,93 ; 5,65 ; 6,45 ; 60)$ & second \\
Hypochlorite dose & Betageneral( $(3,97 ; 9,35 ; 0 ; 40)$ & $\mathrm{ppm}$ \\
Serving size & 50 & $\mathrm{~g}$ \\
\hline
\end{tabular}


Table 2. Dose-response curves: probability of illness

L. monocytogenes Probability of illness

\begin{tabular}{cc}
$(\mathrm{CFU} /$ serving $)$ & $\mathrm{D}_{4 \mathrm{Ci}}(\mathrm{Ni})$ \\
\hline 1 & $1.00 \mathrm{E}-12$ \\
$1.00 \mathrm{E}+03$ & $1.00 \mathrm{E}-09$ \\
$1.00 \mathrm{E}+06$ & $1.00 \mathrm{E}-06$ \\
$1.00 \mathrm{E}+09$ & $1.00 \mathrm{E}-03$ \\
$1.00 \mathrm{E}+12$ & 1.00 \\
\hline
\end{tabular}

Table 3. L. monocytogenes reduction at dipping (Log CFU/g), considering different time and doses of sodium hypochlorite: Control solution $(0.7 \mathrm{ppm})$ and chlorine solutions $(4,8$ and $40 \mathrm{ppm})$

\begin{tabular}{ccccc}
\hline $\begin{array}{c}\text { Time } \\
(\mathrm{min})\end{array}$ & $\begin{array}{c}0,7 \mathrm{ppm} \\
(\mathrm{mean} \pm \mathrm{SD})\end{array}$ & $\begin{array}{c}4 \mathrm{ppm} \\
(\mathrm{mean} \pm \mathrm{SD})\end{array}$ & $\begin{array}{c}8 \mathrm{ppm} \\
(\mathrm{mean} \pm \mathrm{SD})\end{array}$ & $\begin{array}{c}40 \mathrm{ppm} \\
(\mathrm{mean} \pm \mathrm{SD})\end{array}$ \\
\hline 5 & $-1,05 \pm 0,05$ & $-1,57 \pm 0,09$ & $-1,68 \pm 0,06$ & $-1,72 \pm 0,14$ \\
15 & $-1,13 \pm 0,12$ & $-1,31 \pm 0,10$ & $-1,72 \pm 0,17$ & $-1,87 \pm 0,20$ \\
30 & $-1,11 \pm 0,07$ & $-1,91 \pm 0,08$ & $-2,04 \pm 0,20$ & $-1,97 \pm 0,10$ \\
\hline
\end{tabular}

Table 4. L. monocytogenes reduction (Log CFU/g) at washing under running tap water considering different times

\begin{tabular}{cc}
\hline $\begin{array}{c}\text { Time } \\
\text { (seconds })\end{array}$ & $\begin{array}{c}\text { Reduction } \\
(\text { Log CFU/g) }\end{array}$ \\
\hline 10 & $-0,63 \pm 0,06$ \\
20 & $-0,89 \pm 0,03$ \\
30 & $-1,03 \pm 0,06$ \\
45 & $-1,07 \pm 0,01$ \\
60 & $-1,10 \pm 0,04$ \\
\hline
\end{tabular}

Table 5. Probability of illness at home depending on the initial load at retail

\begin{tabular}{llll}
\hline $\begin{array}{l}\text { Initial dose before washing } \\
(\log (\mathrm{UFC} / \mathrm{g})\end{array}$ & Mean & $5 \%$ & $95 \%$ \\
\hline Lognorm $(1,09 ; 0,226)$ & $4,80 \mathrm{E}-11$ & $1,00 \mathrm{E}-11$ & $1,00 \mathrm{E}-10$ \\
3 & $2,79 \mathrm{E}-09$ & $1,00 \mathrm{E}-09$ & $1,00 \mathrm{E}-08$ \\
6 & $2,78 \mathrm{E}-06$ & $1,00 \mathrm{E}-06$ & $1,00 \mathrm{E}-05$ \\
9 & $2,78 \mathrm{E}-03$ & $1,00 \mathrm{E}-03$ & $1,00 \mathrm{E}-02$ \\
\hline
\end{tabular}


Table 6. Sensibility study of different initial load and type of washing

\begin{tabular}{lllll}
\hline $\begin{array}{l}\text { Initial load } \\
(\log (\mathrm{UFC} / \mathrm{g})\end{array}$ & Washing type & Mean & $5 \%$ & $95 \%$ \\
\hline Lognorm(1,09;0,226) & Dipping with bleach & $1,03 \mathrm{E}-11$ & $1,00 \mathrm{E}-11$ & $1,00 \mathrm{E}-11$ \\
Lognorm(1,09;0,226) & Dipping without bleach & $1,79 \mathrm{E}-11$ & $1,00 \mathrm{E}-11$ & $1,00 \mathrm{E}-10$ \\
Lognorm(1,09;0,226) & Washing under running tap water & $4,39 \mathrm{E}-11$ & $1,00 \mathrm{E}-11$ & $1,00 \mathrm{E}-10$ \\
3 & Dipping with bleach & $8,61 \mathrm{E}-10$ & $1,00 \mathrm{E}-10$ & $1,00 \mathrm{E}-09$ \\
3 & Dipping without bleach & $1,00 \mathrm{E}-09$ & $1,00 \mathrm{E}-09$ & $1,00 \mathrm{E}-09$ \\
3 & Washing under running tap water & $2,69 \mathrm{E}-09$ & $1,00 \mathrm{E}-09$ & $1,00 \mathrm{E}-08$ \\
6 & Dipping with bleach & $8,65 \mathrm{E}-07$ & $1,00 \mathrm{E}-07$ & $1,00 \mathrm{E}-06$ \\
6 & Dipping without bleach & $1,00 \mathrm{E}-06$ & $1,00 \mathrm{E}-06$ & $1,00 \mathrm{E}-06$ \\
6 & Washing under running tap water & $2,69 \mathrm{E}-06$ & $1,00 \mathrm{E}-06$ & $1,00 \mathrm{E}-05$ \\
9 & Dipping with bleach & $8,59 \mathrm{E}-04$ & $1,00 \mathrm{E}-04$ & $1,00 \mathrm{E}-03$ \\
9 & Dipping without bleach & $1,00 \mathrm{E}-03$ & $1,00 \mathrm{E}-03$ & $1,00 \mathrm{E}-03$ \\
9 & Washing under running tap water & $2,69 \mathrm{E}-03$ & $1,00 \mathrm{E}-03$ & $1,00 \mathrm{E}-02$ \\
\hline
\end{tabular}

